\title{
Heuristic Operator for Reliability Assessment of Frame Structures
}

\author{
Ali Kaveh $^{1 *}$, Seyed Rohollah Hoseini Vaez ${ }^{2}$, Pedram Hosseini ${ }^{3}$, Mohammad Ali Fathali $^{2}$ \\ ${ }^{1}$ School of Civil Engineering, Iran University of Science and Technology, Narmak, Tehran 16846-13114, Iran \\ 2 Department of Civil Engineering, Faculty of Engineering, University of Qom, Qom 3716146611, Iran \\ ${ }^{3}$ Faculty of Engineering, Mahallat Institute of Higher Education, Mahallat 3781151958, Iran \\ * Corresponding author, e-mail: alikaveh@iust.ac.ir
}

Received: 25 November 2020, Accepted: 22 January 2021, Published online: 29 January 2021

\begin{abstract}
In structural design of steel frames, in order to achieve proper safety, the effect of uncertainties in the design and loading parameters of the structure must be considered. This approach is obtained by defining a reliability index. In this study, the Modified Dolphin Monitoring (MDM) operator was used to evaluate the reliability index of three well-known steel frame structures based on the Hasofer-Lind method. The reliability index was evaluated using the EVPS and VPS algorithms and with considering the MDM operator on them. The constraint of the last story drift is considered as limit state function. The random variables consist of external loads, modulus of elasticity, moment of inertia and cross-sectional areas. According to the number of evaluations of the limit state function, the results show the efficiency of this method in comparison to the Monte Carlo simulation method. Also, the values of the most probable point (MPP) are examined.
\end{abstract}

Keywords

frame structures, reliability index, optimization algorithms, limited state function

\section{Introduction}

Due to the random nature of the mechanical, geometrical and external loading properties of the structures that cause uncertainties in the structural design, nowadays, it is essential to consider these uncertainties in structural engineering. To address these uncertainties, reliability assessment methods were developed [1-6]. Assessment of failure probability is one of the critical parts of this topic, which is performed by formalizing a Limit State Function (LSF) while considering random variables. To calculate the failure probability, there are two main categories, namely Moment and Simulation methods. The Monte Carlo Simulation (MCS) method is a very efficient method of calculating the failure probability, but it requires a lot of estimations of the LSF [7-9].

On the other hand, the FORM and SORM methods, which are part of the moment methods, are useful in structural engineering problems [10-16]. A reliability index, which defined as the shortest geometric distance between the origin of standard normal space and the LSF, is presented. The above definition can be considered as an optimization problem, such that the minimum distance between the LSF from the origin of the standard normal space is defined as the objective function and the limit state function as constraints. So, this problem can be solved by meta-heuristic algorithms [17-19].

The use of meta-heuristic algorithms has always been of interest and has been used successfully in various fields of structural engineering, such as optimal design, damage detection, and so on [20-25].

One of the meta-heuristic algorithms, which has recently been presented and successfully used in various fields, is the Vibrating Particles Systems (VPS) algorithm [26]. This algorithm presented by Kaveh and Ilchi Ghazaan in 2017, an Enhanced version of the VPS (EVPS) algorithm introduced by Kaveh et al. [27] in 2019.

Improving the performance of meta-heuristic algorithms has always been considered, so the methods that enhance the performance of meta-heuristic algorithms are highly regarded. In 2016, Kaveh and Farhoudi [28] introduced Dolphin Monitoring (DM) Operator that can be applied to all meta-heuristic algorithms. In 2018, Kaveh et al. [29] enhanced the performance of the DM operator by making 
some changes in the mechanisms of the operator. It should be noted that these two operators control the population distribution in each iteration and somewhat prevent to entrap in local optima. The Enhanced Dolphin Monitoring (MDM) operator has been used successfully in several investigations so far.

In the present study, the optimal design variables of well-known references were selected and the reliability index of the results was evaluated using the EVPS and VPS algorithms (by defining the objective function as the minimum distance between the limit state function from the origin of the standard normal space) and by adding the MDM operator on it (EVPS-MDM) under the impact of some constraints that described in each problem. Finally, the computed index value with the meta-heuristic algorithms is compared with the MCS method.

\section{Metaheuristic algorithms and problem formulations} The EVPS and VPS (with MDM operator) algorithms for reliability assessment of frame structures. In this section, the EVPS algorithm and the MDM operator are briefly described. Then, in order to investigate the performance of the EVPS and VPS algorithm as well as to evaluate the effect of the MDM operator, an objective function based on the reliability assessment is formulated. Finally, the formulation of the reliability assessment and the objective function is presented.

\subsection{Metaheuristic algorithms}

This study uses the effect of the MDM operator on EVPS and VPS algorithms (EVPS-MDM and VPS-MDM, respectively) to solve the problems of reliability assessment of frame structures. The following is a description of the EVPS and VPS algorithms and the MDM operator:

\subsubsection{The Vibrating Particles System (VPS) and Enhanced Vibrating Particles System (EVPS) algorithms}

The VPS algorithm is based on free vibration of single degree of freedom systems with viscous damping, this algorithm generates the next population bases on current population and historically best position in order to have a proper balance between exploration and exploitation phase [26]. The EVPS algorithm is an enhanced version of the VPS algorithm and utilizes some new mechanisms to reaching the optimal solution. In this approach, two new parameters, Memory and OHB (One of the Historically Best positions), were introduced to enhance the performance of the meta-heuristic algorithm, and changes were also made to create a new population for the next iteration. In fact, population generation is perform with three different mechanism, each of which is likely to be selected $\omega_{1}, \omega_{2}$ and $\omega_{3}$, respectively. The schematic image of the population generated for the next iteration is shown in Fig. 1.

Formulation 1

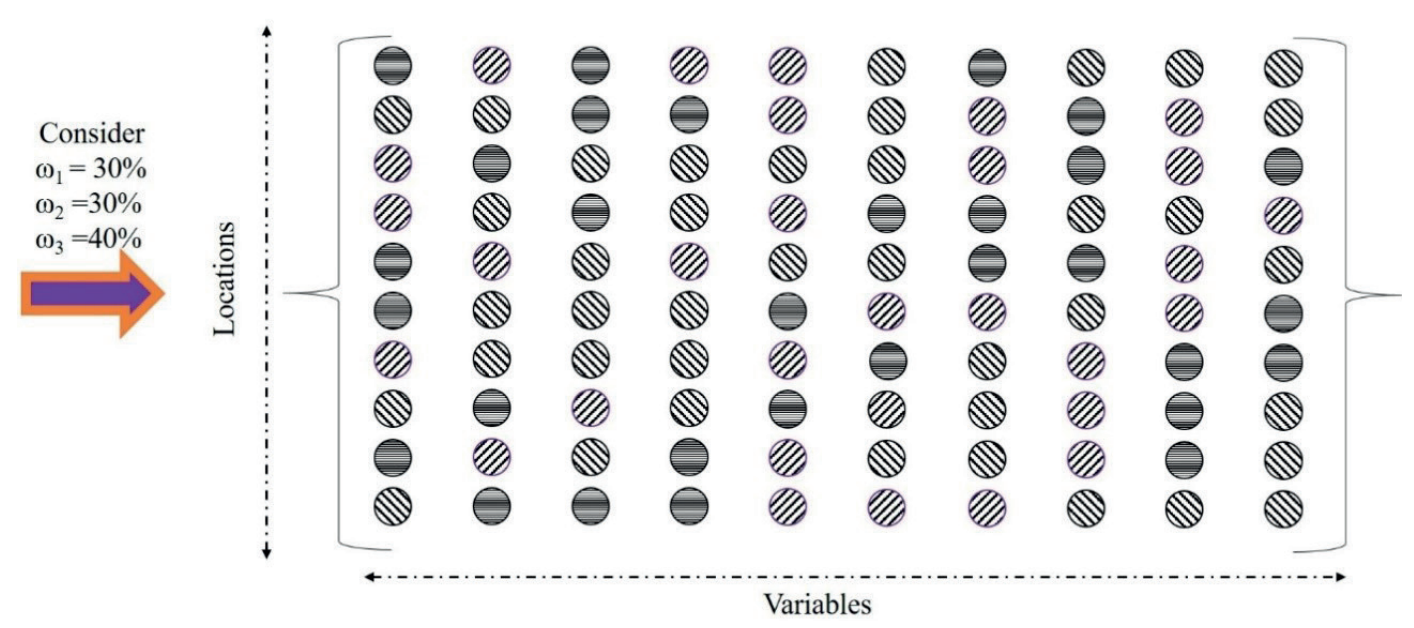

Fig. 1 Schematic image of the population generated for the next iteration of the EVPS algorithm 


\subsubsection{The MDM operator}

The MDM operator is the modified version of Dolphin Monitoring (DM) [28]. The DM was presented by Kaveh and Farhoudi [28]. This operator can be applied to all meta-heuristic algorithms and tries to enhance the performance of the meta-heuristic algorithms with its approaches.

Usually, each algorithm, along with the advantages, may have disadvantages. For example, an algorithm may reach a great answer for some group of problems and may be too weak for other groups, which may be due to incorrect setting of algorithm parameters for each problem, or the inability of the algorithm to solve some problems. By investigating how meta-heuristic algorithms converge, it can be concluded that early convergence in algorithms is usually the result of entrap in local optima. Therefore, the MDM operator qualifies the scattering of the population in each iteration and variable. This mechanism can be useful to get out of entrap in local optima. This operator defines an interval (shown in Fig. 2) and controls the population dispersion in this interval.

If the population distribution is more or less than the desired value in each iteration, this equilibrium is established by some mechanisms. Fig. 3 illustrates how this operator works if the population distribution in the defined range is $60 \%$ (As stated as $\mathrm{Mp}$ ).

\subsection{Reliability assessment}

The parameters of the structure, such as material properties and geometric characteristics of elements, have probabilistic uncertainties [30]. In the theory of reliability, these parameters are called random variables, each of which

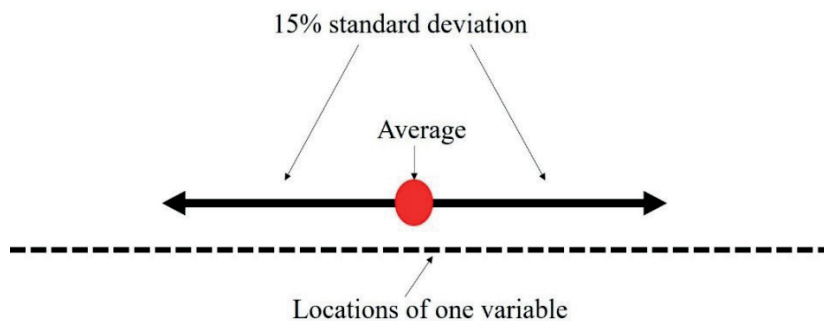

Fig. 2 The defined interval for the MDM operator

has a statistical distribution with characteristics including mean and standard deviation (or coefficient of variation). The effect of these uncertainties on the satisfaction of various constraints such as stress of elements, applied force, drift of a story and etc. can be investigated. More likely to satisfy a constraint by the structure means the more reliable response of the structure to the considered constraint. In the reliability assessment, to investigate this issue, a function of random variables called the limit state function $(g)$ is introduced. $R$ and $Q$ parameters are the strength of the structure (or the allowable limit of the constraint) and the applied load effect to it (or the result of structural analysis). For the constraint $R>Q$ the LSF is defined as follows:

$g(R, Q)=R-Q$

The positive $(g>0)$ and negative $(g \leq 0)$ value of the LSF represents safety and failure region, respectively. The probability of placing a structure in the failure region, the probability of failure, the probability of placing it in the safety region and the probability of safety of the structure are expressed by $\mathrm{P}[g \leq 0],\left(P_{f}\right), \mathrm{P}[g>0]$ and $\left(P_{s}\right)$, respectively.

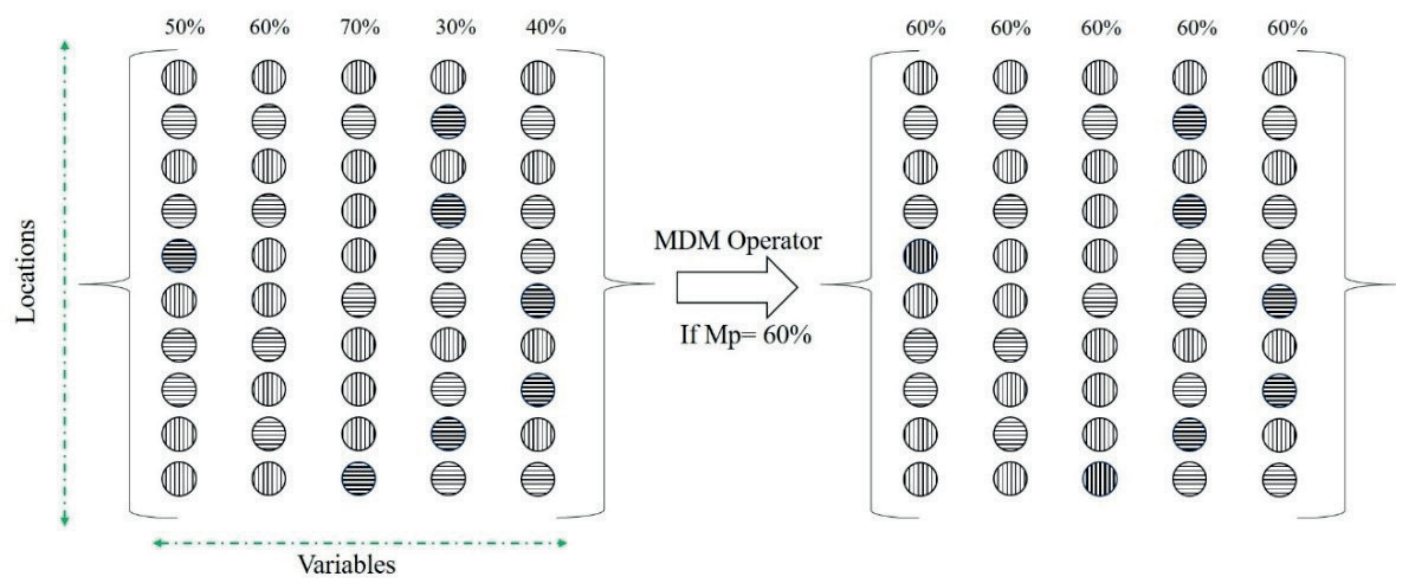

Fig. 3 The operation of the MDM operator 
In reliability analysis, the safety level of a structure can be determined based on the probability of failure (or safety) or an indicator called the reliability index $(\beta)$. The following equation (Eq. (2)) represents relationship between this index and the probability of failure which is based on a linear approximation assumption:

$\beta=\phi^{-1}\left(1-P_{f}\right)$,

where $\phi^{-1}$ is the inverse of the cumulative density function of the normal distribution.

Different methods have been suggested to evaluate the $\beta$. A group of these methods calculates the reliability index based on the definition provided by Hasofer and Lind [31]. According to this definition, the $\beta$ is equal to the smallest distance of points located on the boundary of safe space and failure $(g=0)$ from the center of the standard normal coordinate of random variables. This point is called the most probable point (MPP) of failure. Therefore, $\beta$ can be defined and calculated according to the following equation (Eq. (3)):

$\beta=\min ($ dist $)$,

where, dist is the vector of the distance of points on the safe space boundary and failure from the center of the standard normal coordinate of random variables. This distance for the $s$ th point on this boundary is calculated according to the following equation (Eq. (4)):

$$
\operatorname{dist}_{s}=\sqrt{\boldsymbol{u}_{s}^{t} \boldsymbol{u}_{s}}=\sqrt{\sum_{i=1}^{n} u_{s, i}{ }^{2}},
$$

where $\boldsymbol{u}_{s}$ and $u_{s, i}$ are the vector values of the random variables and the $i$ th random variable of the s point in the standard normal coordinate. Also, $n$ is the number of random variables. Random variables are converted to the standard normal distribution by the normal distribution according to the following equation (Eq. (5)):

$u_{i}=\frac{x_{i}-\mu_{x_{i}}}{\sigma_{x_{i}}}$,

where $x_{i}$ is random variable with normal distribution, $\sigma_{x i}$ and $\mu_{x i}$ are the standard deviation and mean, respectively.

The above definition, with linear approximation assumption of LSF, called the First Order Reliability Method (FORM).

\subsection{Objective function}

To calculate the reliability index according to the Hasofer and Lind definition, an optimization problem based on random variables $(\boldsymbol{X})$ can be defined as follows: find

$$
\boldsymbol{X}=\left\{x_{1}, x_{2}, \ldots, x_{n}\right\}
$$

to minimize $\operatorname{dist}(\boldsymbol{X})=\sqrt{\boldsymbol{u}(\boldsymbol{X})^{T} \boldsymbol{u}(\boldsymbol{X})}=\sqrt{\sum_{i=1}^{n}\left[\left(x_{i}-\mu_{x_{i}}\right) / \sigma_{x_{i}}\right]^{2}}$

subject to $g(X)=0$

where $\quad \boldsymbol{x}_{\min } \leq \boldsymbol{x} \leq \boldsymbol{x}_{\max }$

By solving the above problem, the reliability index of the limit state function $(g)$ is obtained by considering the probability variables $\boldsymbol{X}$.

\section{Numerical examples}

Three well-known frame structures which optimized (weight optimization) by other researchers are selected for determining the reliability index, using EVPS, VPS, EVPS-MDM and VPS-MDM algorithms. The $\beta$ index in all examples is calculated based on maximum lateral displacement of the last story probability constraints. Random variables which assumed in all problems are consisting of: modulus of elasticity $(E)$, external load $(P)$ and cross-sectional area $(A)$ and moment of inertia $(I)$ of the elements, respectively (the group of elements). A normal distribution are considered for all random variables. Coefficient of variations $(\mathrm{COV})$ of external loads is $10 \%$ and the other random variables are considered $5 \%$.

To guarantee the efficiency of the algorithms, the $\beta$ index for all problems was obtained by both of the algorithms in 30 independent runs. The maximum number of iterations and population size of all algorithms are 1000 and 100, respectively. The number of assumed instance $(n)$ for all random variables in each problem is 106 . Also, to measure the precision of each algorithm in assessing the $\beta$ index, this index has been calculated 30 times in each problem using the Monte Carlo simulation (MCS) method, which is a common method for evaluating the $\beta$ index. The average of MCS results obtained for each problem have been reported as MCS reliability index. It is note-worthy, the number of MCS instances in all cases is $2 \times 10^{5}$.

Reliability index in all three frames has been calculated to determine the probability that the amount of lateral displacement of the roof $\left(\Delta_{T}\right)$ is less than the allowable value of $1 / 300$ of the frame height $(H)$ :

$g(\boldsymbol{X})=(H / 300)-\Delta_{T}$

\subsection{A 1-bay 10-story frame}

Fig. 4 illustrates the schematic, applied loads and the numbering of the member groups for this frame structure. This frame consists of 11 joints and 30 elements. The ele- 


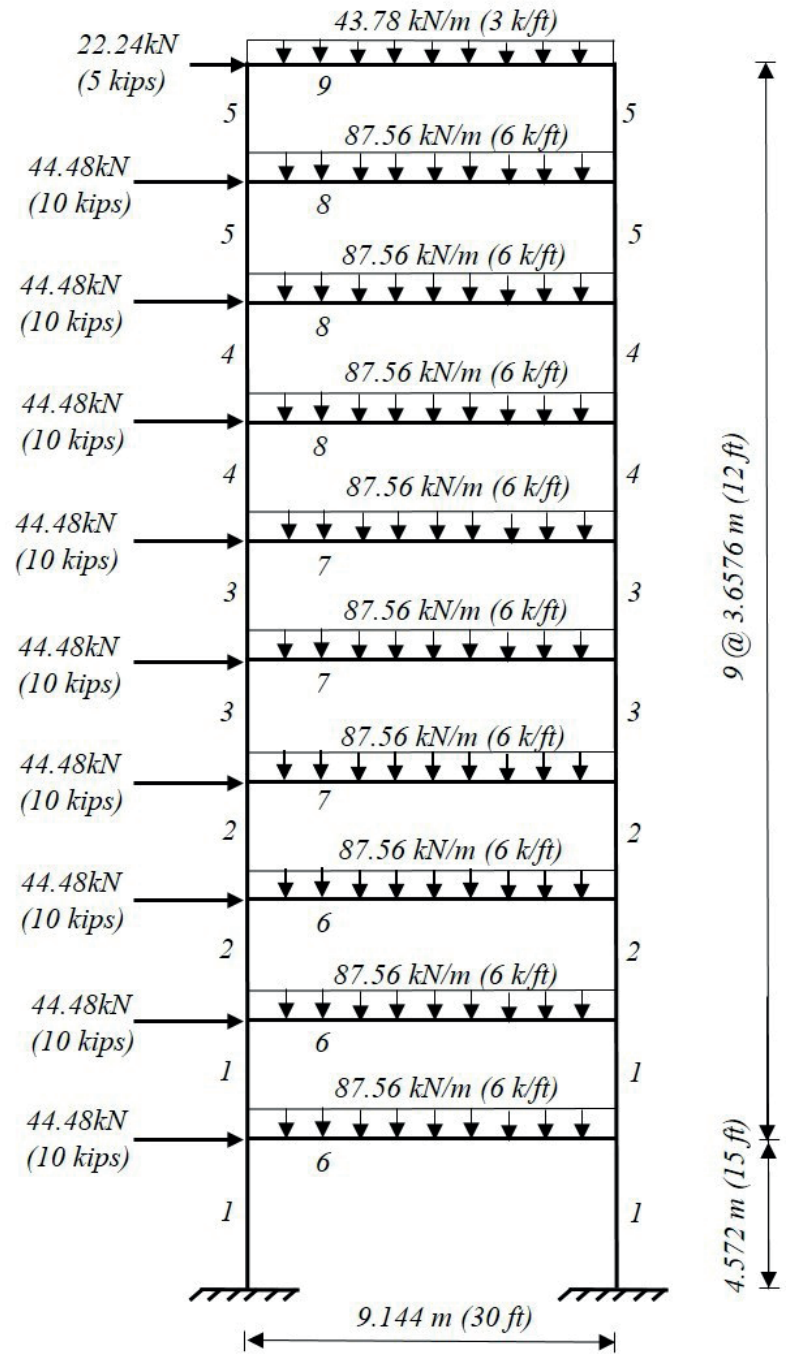

Fig. 4 Schematic of the 1-bay 10-story frame

ment grouping results in 4 beam sections and 5 column sections. The material has a modulus of elasticity equal to $E=200 \mathrm{GPa}(29000 \mathrm{ksi})$ and the yield stress of $f_{y}=248.2 \mathrm{MPa}$ (36 ksi). The number of random variables in this problem are 23 variables (consisting of 9 cross-sectional
Table 1 The probabilistic properties of random variables for 1-bay 10 -story frame

\begin{tabular}{lcccc}
\hline $\begin{array}{l}\text { Random Variable, } \\
\text { unit }\end{array}$ & $\begin{array}{c}\text { Type of } \\
\text { probability } \\
\text { distribution }\end{array}$ & $\begin{array}{c}\text { Number } \\
\text { of } \\
\text { variables }\end{array}$ & Mean & COV \\
\hline $\begin{array}{l}\text { Modulus of } \\
\text { elasticity }(E), \mathrm{GPa}\end{array}$ & Normal & 1 & 200 & $5 \%$ \\
$\begin{array}{l}\text { Gravity loads, } \\
\mathrm{kN} / \mathrm{m}\end{array}$ & Normal & 2 & $\begin{array}{c}87.56 \text { and } \\
43.78\end{array}$ & $5 \%$ \\
$\begin{array}{l}\text { Lateral load, kN } \\
\text { Normal }\end{array}$ & 2 & $\begin{array}{c}44.48 \text { and } \\
22.24\end{array}$ & $5 \%$ \\
$\begin{array}{l}\text { Cress-sectional }(A) \\
\text { area }\end{array}$ & Normal & 9 & $\begin{array}{c}\text { According } \\
\text { to Table } 2\end{array}$ & $5 \%$ \\
$\begin{array}{l}\text { Moment of } \\
\text { inertia }(I)\end{array}$ & Normal & 9 & $\begin{array}{c}\text { According } \\
\text { to Table } 2\end{array}$ & $5 \%$ \\
\hline
\end{tabular}

Table 2 Selected design sections of 1-bay 10-story frame

\begin{tabular}{lccc}
\hline $\begin{array}{l}\text { Element group } \\
\text { number }\end{array}$ & Section & $\begin{array}{c}\text { Element group } \\
\text { number }\end{array}$ & Section \\
\hline 1 & $\mathrm{~W} 14 \times 233$ & 6 & $\mathrm{~W} 33 \times 118$ \\
2 & $\mathrm{~W} 14 \times 176$ & 7 & $\mathrm{~W} 30 \times 99$ \\
3 & $\mathrm{~W} 14 \times 145$ & 8 & $\mathrm{~W} 27 \times 84$ \\
4 & $\mathrm{~W} 14 \times 99$ & 9 & $\mathrm{~W} 21 \times 44$ \\
5 & $\mathrm{~W} 12 \times 65$ & & \\
\hline
\end{tabular}

area, 9 moment of inertia, 2 gravity load and 2 lateral load and modulus of elasticity) which their probabilistic properties are reported in Table 1. The reliability index for probabilistic constraints is the maximum lateral displacement of the last story (less than allowable value equal to $12.5 \mathrm{~cm}$ ). The reliability index is calculated for the optimal design obtained from the SDE algorithm presented in Table 2 [21].

Figs. 5 and 6 show the performance of the algorithms for best and mean results in 30 independent runs, respectively. Fig. 7 shows the comparison of the results of all algorithms in 30 independent runs for the 1-bay 10-story frame in descending order for both algorithms. The performance
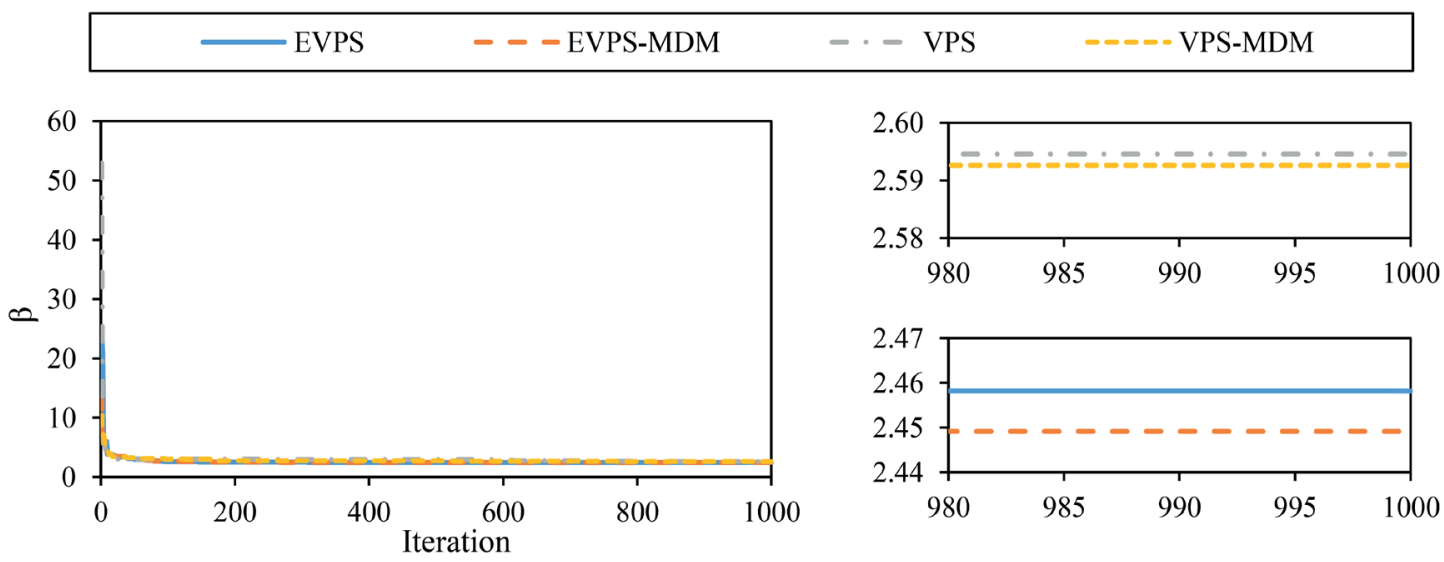

Fig. 5 The convergence diagrams for the best run of the both algorithms for the 1-bay 10-story frame 

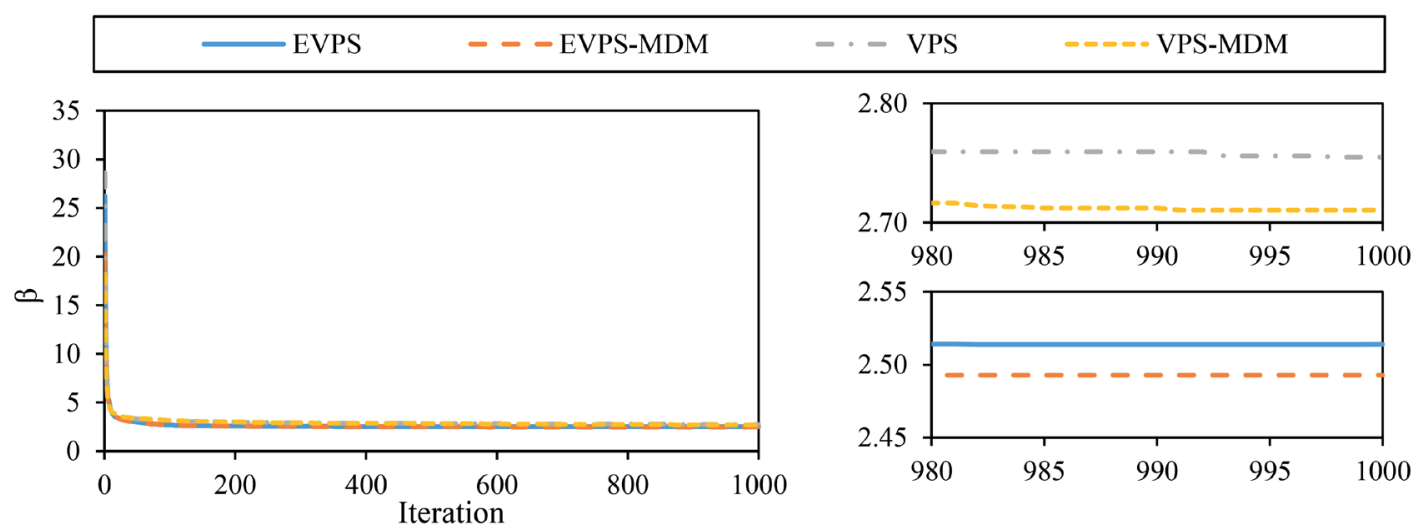

Fig. 6 The convergence diagrams for the average runs of the both algorithms for the 1-bay 10-story frame

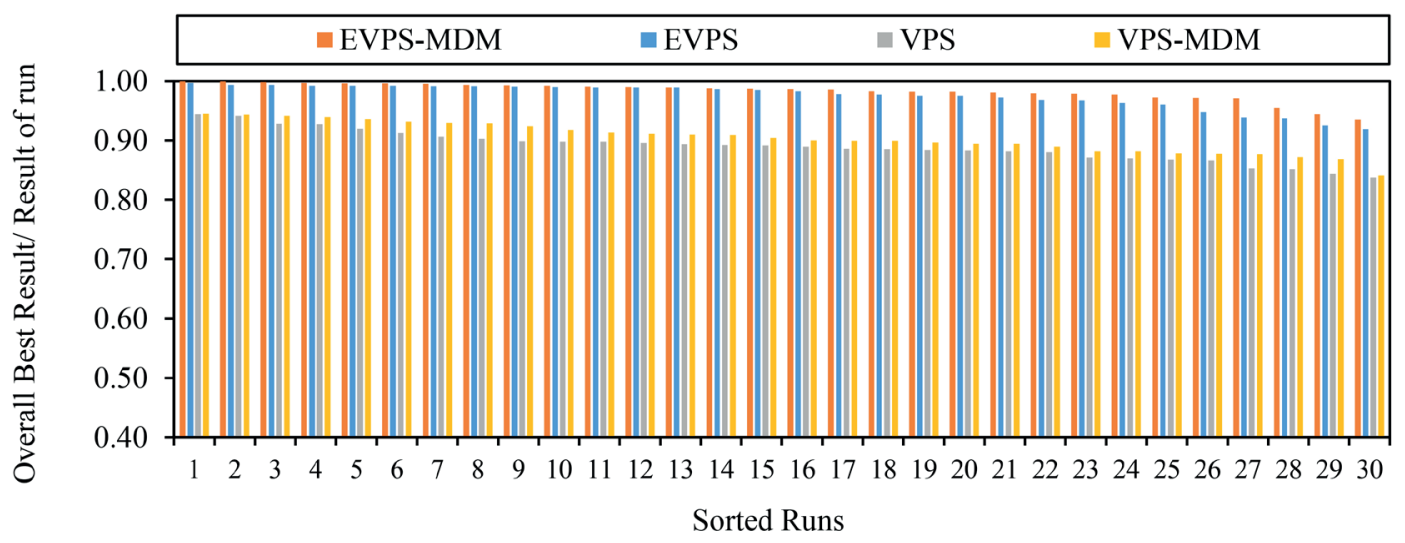

Fig. 7 Comparison of the results of all algorithms in 30 independent runs for the 1-bay 10-story frame

of the EVPS-MDM and VPS-MDM algorithms are better than the EVPS and VPS algorithms, respectively, as shown in the Figs. 5, 6 and 7. The best, the worst, and the mean of the answers of both algorithm and the value of the $\beta$ index achieved from the MCS method are reported in Table 3. In this table the capability of the EVPS-MDM and VPS-MDM to find the reliability index are better than EVPS and VPS algorithms, respectively and also, this algorithm has found a $\beta$ index with an appropriate difference compared to the MCS method. Fig. 8 presents the statistical scattering of the solution of 30 independent runs of the algorithm for the 1-bay 10-story frame.

Fig. 9 shows the values of random variables at the MPP obtained from each algorithm on the Probability Density Function (PDF) of standard normal distribution diagram. According to this figure, it can be seen that the values of the cross-sectional areas and the moment of inertia of the group of elements are approximately the same as the mean values, and decreasing the modulus of elasticity and increasing the lateral load relative to their mean values has created the MPP.

\subsection{A 3-bay 15-story frame}

Fig. 10 illustrates the schematic, applied loads and the numbering of the member groups for this frame structure. This frame consists of 64 joints and 105 elements. The element grouping results in 1 beam sections and 10 column sections. The material has a modulus of elasticity equal to $E=200 \mathrm{GPa}(29000 \mathrm{ksi})$ and the yield stress of $f_{y} \mathrm{v}=248.2 \mathrm{MPa}(36 \mathrm{ksi})$. The number of random variables in this problem are 25 variables (consisting of 11 cross-sectional area, 11 moment of inertia, 1 gravity load and 1 lateral load and modulus of elasticity) which their probabilistic properties are reported in Table 4.

Table 3 Summary of the results obtained by algorithms for the 1-bay 10 -story frame

\begin{tabular}{lccccc}
\hline & EVPS & EVPS-MDM & VPS & VPS-MDM & MCS \\
\hline Best $\beta$ & 2.4581 & 2.4491 & 2.5946 & 2.5926 & - \\
Average $\beta$ & 2.5140 & 2.4929 & 2.7548 & 2.7105 & 2.4174 \\
Worst $\beta$ & 2.6658 & 2.6190 & 2.9265 & 2.9146 & - \\
$\operatorname{Std} \beta$ & 0.0571 & 0.0402 & 0.0821 & 0.0788 & 0.0186 \\
\hline
\end{tabular}




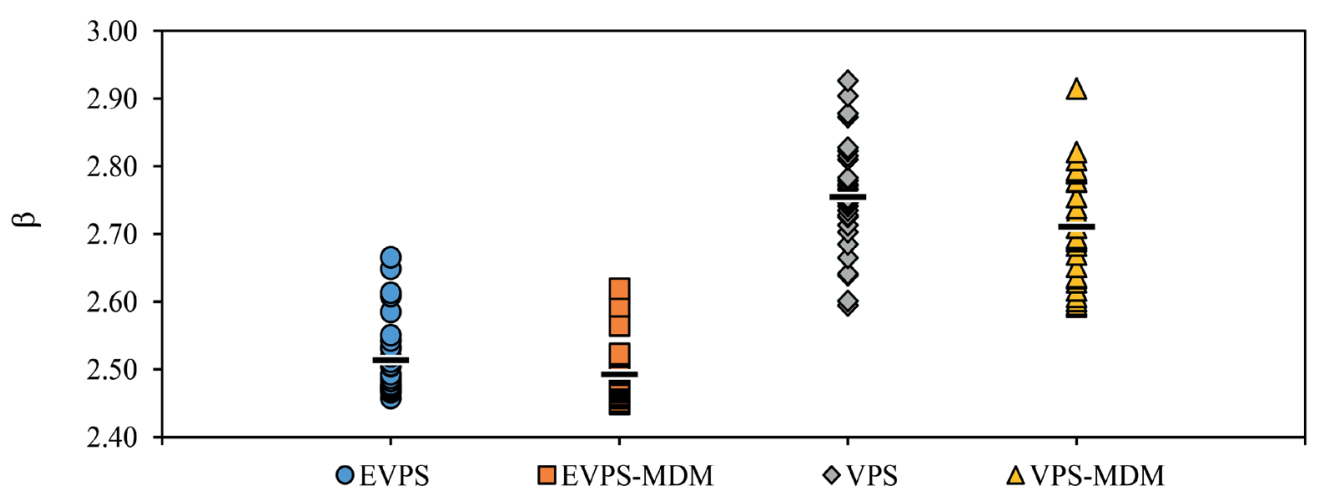

Fig. 8 Statistical scattering of the solution of 30 independent runs of the algorithm for the 1-bay 10-story frame
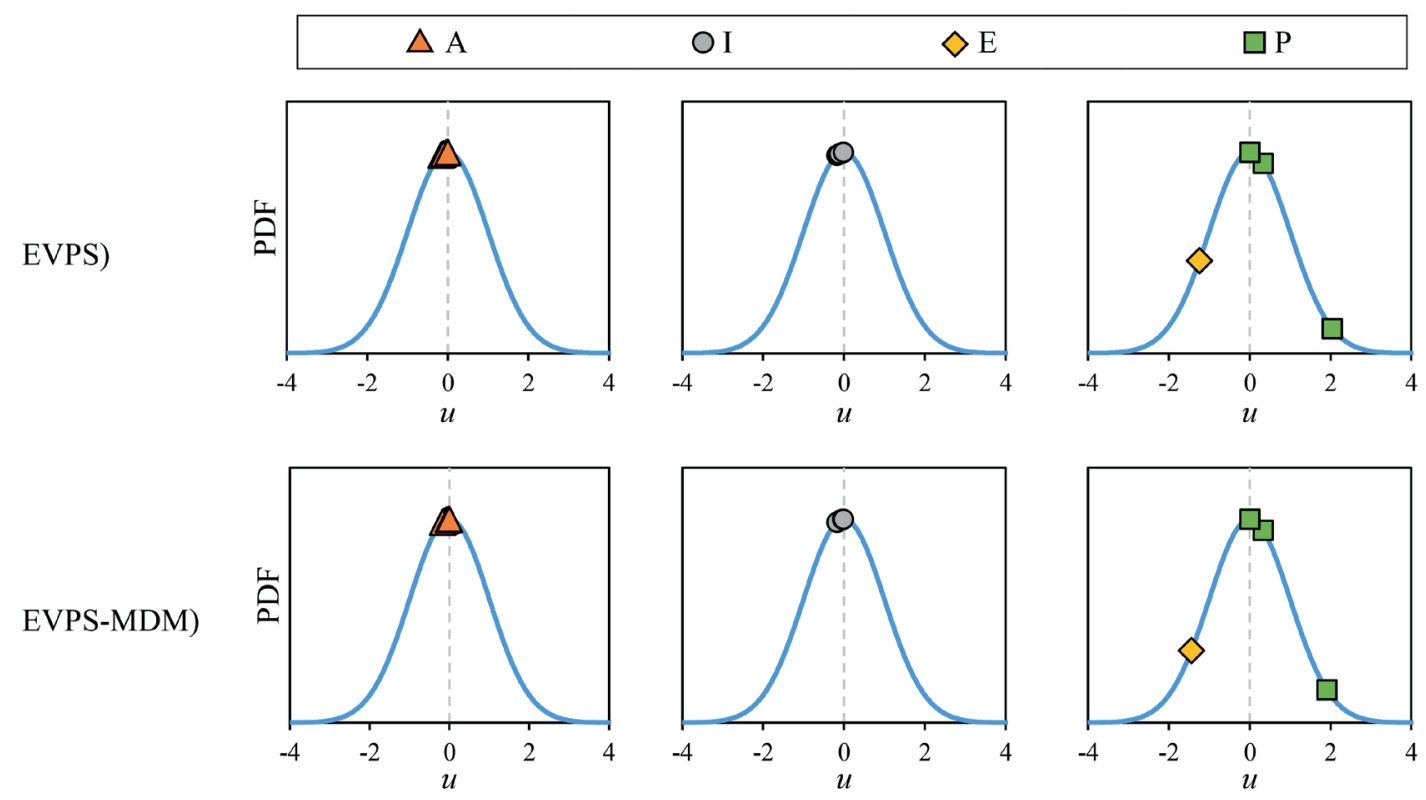

VPS)
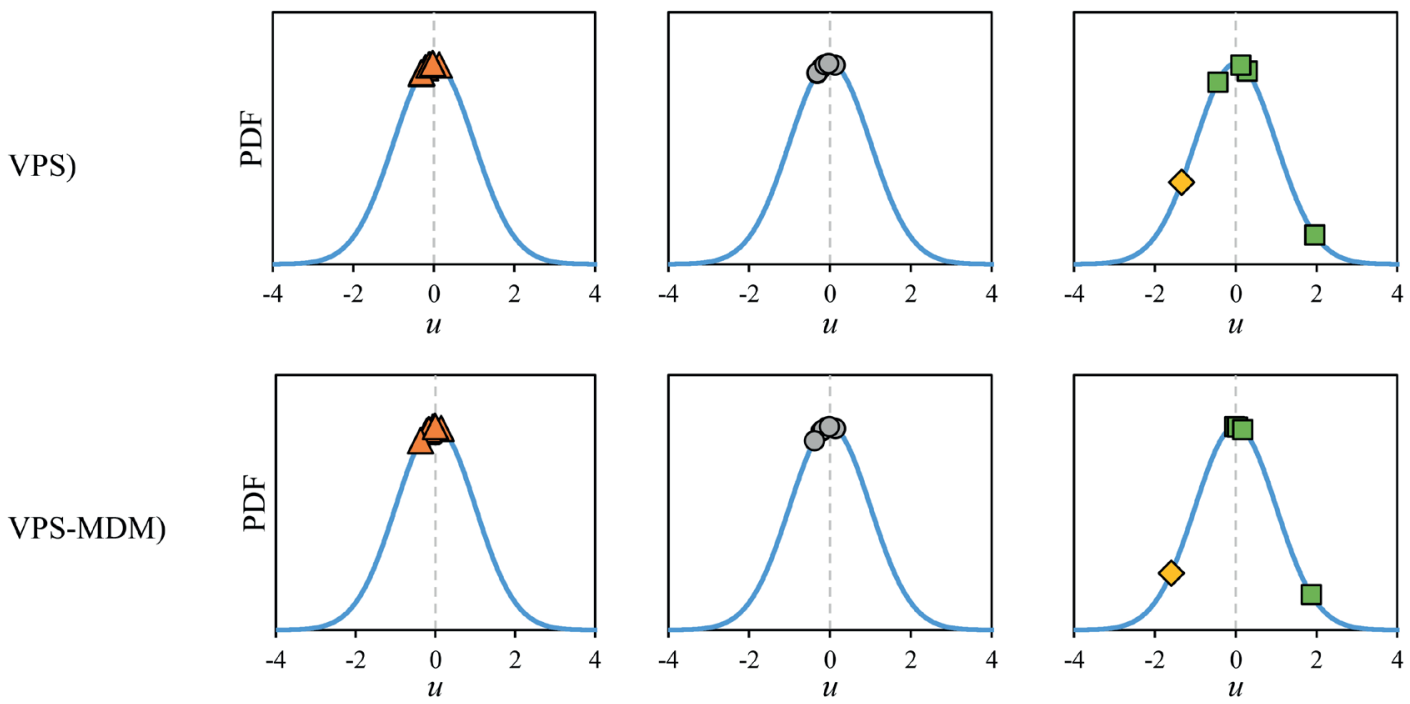

Fig. 9 The MPP in standard normal space (U-space) obtained from each algorithm for the 1-bay 10-story frame 
$\mathrm{W} 1=50 \mathrm{kN} / \mathrm{m}(3.42 \mathrm{kips} / \mathrm{ft})$

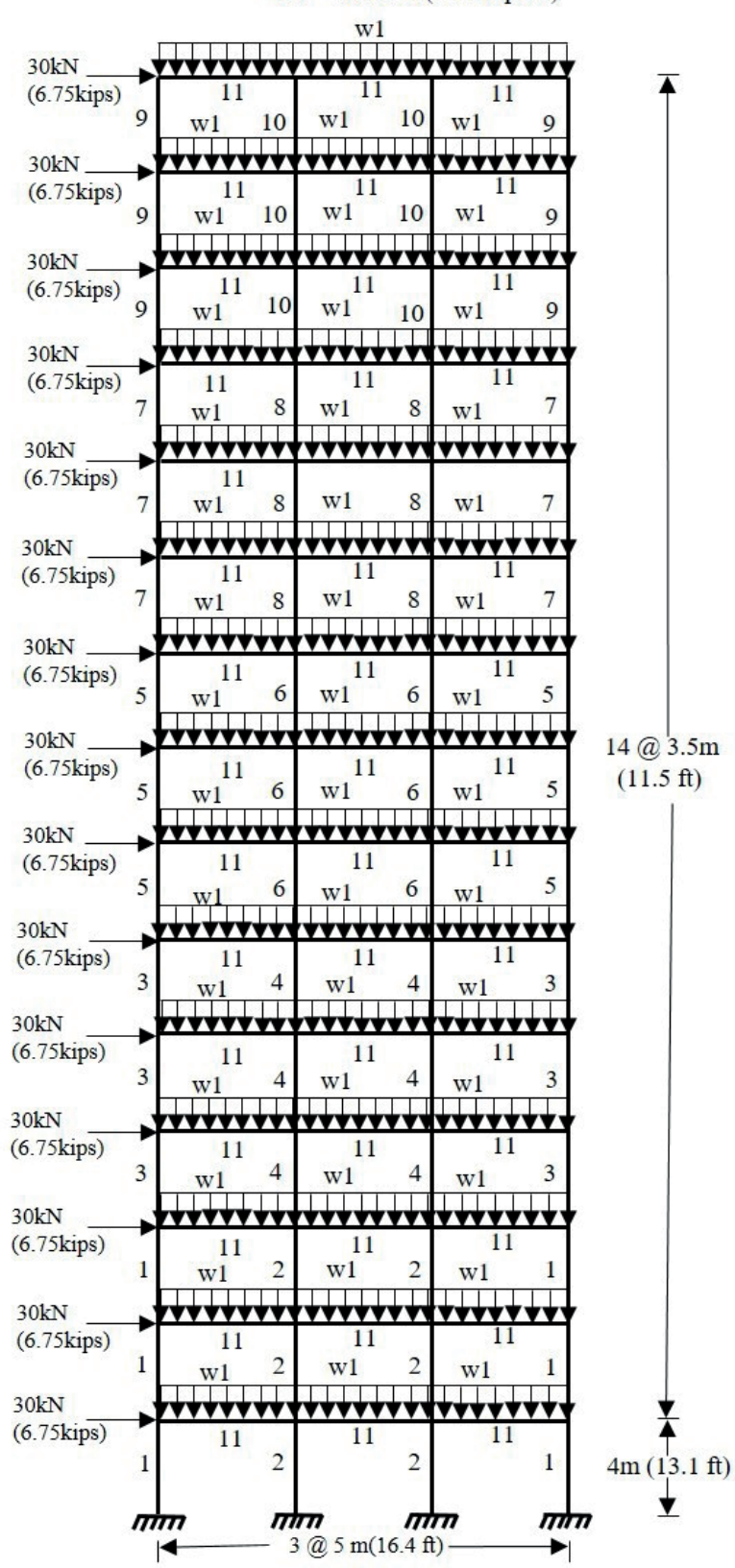

The reliability index for probabilistic constraints is the maximum lateral displacement of the last story (less than allowable value equal to 6.94 in or $17.69 \mathrm{~cm}$ ). The reliability index is calculated for the optimal design obtained from the SDE algorithm presented in Table 5 [21].

Figs. 11 and 12 show the performance of the algorithms for best and mean results in 30 independent runs, respectively. Fig. 13 shows the comparison of the results of all algorithms in 30 independent runs for the 3-bay 15-story frame in descending order for both algorithms. The performance of the EVPS-MDM and VPS-MDM algorithms are better than the EVPS and VPS algorithms, respectively, as shown in the Figs. 11, 12 and 13. The best, the worst, and

Table 4 The probabilistic properties of random variables for 3-bay

\begin{tabular}{lcccc}
\multicolumn{4}{c}{ 15-story frame } \\
\hline $\begin{array}{l}\text { Random Variable, } \\
\text { unit }\end{array}$ & $\begin{array}{c}\text { Type of } \\
\text { probability } \\
\text { distribution }\end{array}$ & $\begin{array}{c}\text { Number } \\
\text { of } \\
\text { variables }\end{array}$ & Mean & COV \\
\hline $\begin{array}{l}\text { Modulus of } \\
\text { elasticity }(E), \mathrm{GPa}\end{array}$ & Normal & 1 & 200 & $5 \%$ \\
$\begin{array}{l}\text { Gravity loads, } \mathrm{kN} / \mathrm{m} \\
\text { Lateral load, } \mathrm{kN}\end{array}$ & Normal & 1 & 50 & $5 \%$ \\
$\begin{array}{l}\text { Cross-sectional } \\
\text { area }(A)\end{array}$ & Normal & 1 & 30 & $5 \%$ \\
$\begin{array}{l}\text { Moment of } \\
\text { inertia }(I)\end{array}$ & Normal & 11 & $\begin{array}{c}\text { According } \\
\text { to Table } 5\end{array}$ & $5 \%$ \\
\hline
\end{tabular}

Table 5 Selected design sections of 3-bay 15-story frame

\begin{tabular}{lccc}
\hline $\begin{array}{l}\text { Element group } \\
\text { number }\end{array}$ & Section & $\begin{array}{c}\text { Element group } \\
\text { number }\end{array}$ & Section \\
\hline 1 & $\mathrm{~W} 14 \times 90$ & 7 & $\mathrm{~W} 14 \times 48$ \\
2 & $\mathrm{~W} 36 \times 170$ & 8 & $\mathrm{~W} 12 \times 65$ \\
3 & $\mathrm{~W} 27 \times 84$ & 9 & $\mathrm{~W} 6 \times 25$ \\
4 & $\mathrm{~W} 24 \times 104$ & 10 & $\mathrm{~W} 12 \times 40$ \\
5 & $\mathrm{~W} 14 \times 61$ & 11 & $\mathrm{~W} 21 \times 44$ \\
6 & $\mathrm{~W} 30 \times 90$ & & \\
\hline
\end{tabular}

Fig. 10 Schematic of the 3-bay 15-story frame

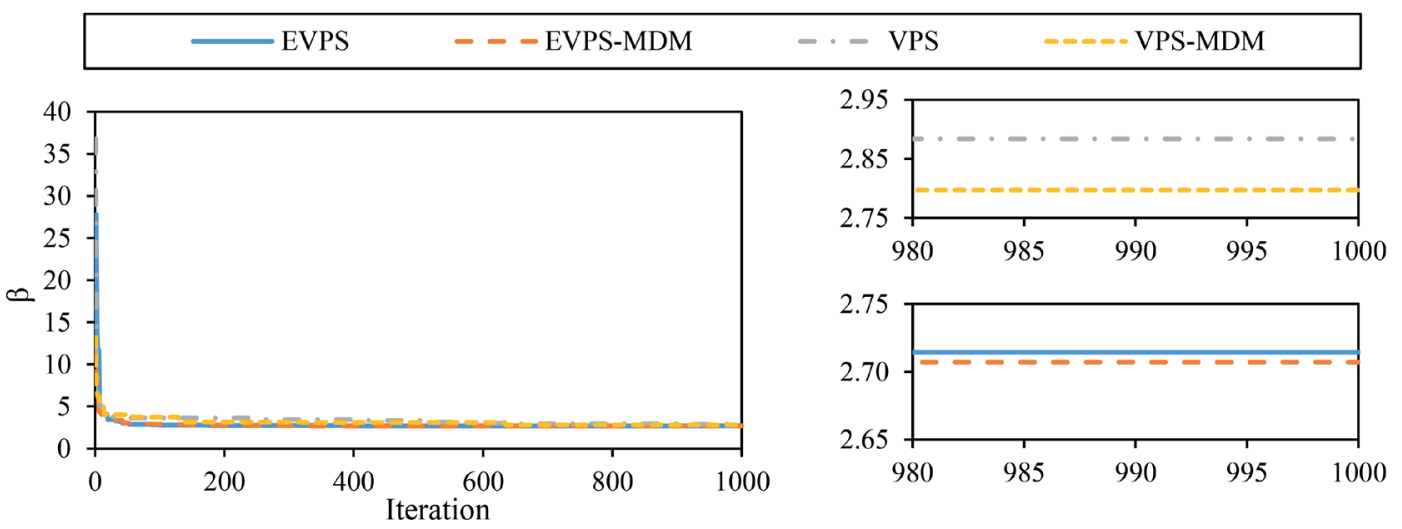

Fig. 11 The convergence diagrams for the best run of the both algorithms for the 3-bay 15-story frame 


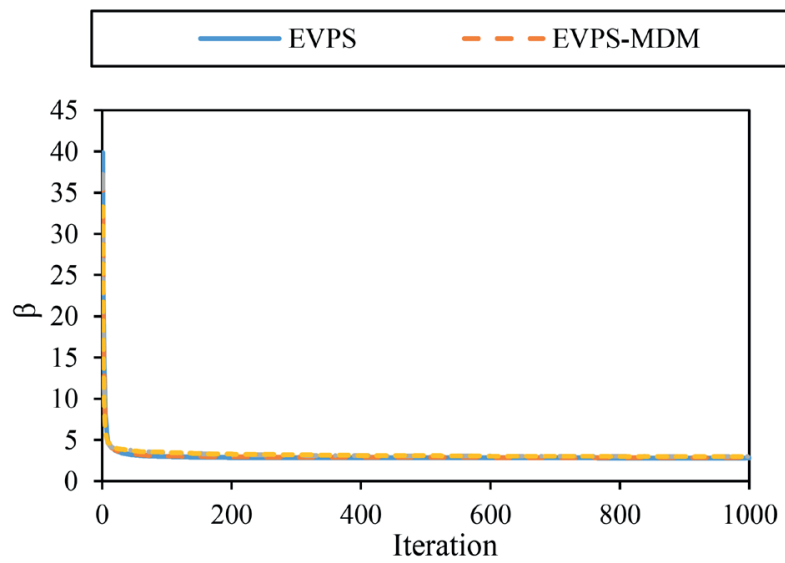

$-\cdots$ VPS - - - - VPS-MDM
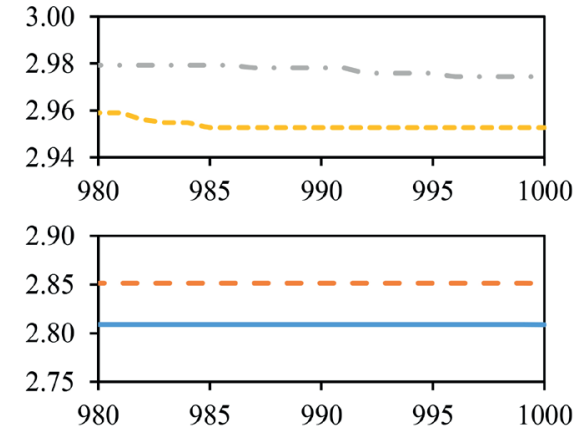

Fig. 12 The convergence diagrams for the average runs of the both algorithms for the 3-bay 15-story frame

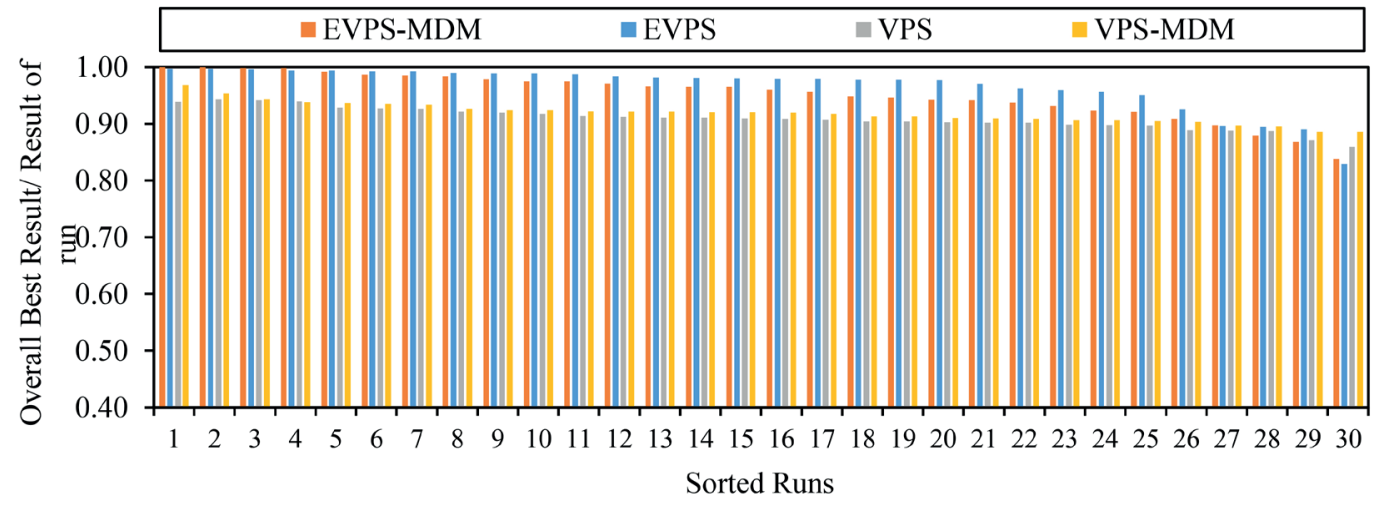

Fig. 13 Comparison of the results of both algorithms in 30 independent runs for the 3-bay 15-story frame

the mean of the answers of both algorithm and the value of the $\beta$ index achieved from the MCS method are reported in Table 6. In this table the capability of the EVPS-MDM and VPS-MDM to find the reliability index are better than EVPS and VPS algorithms, respectively and also, this algorithm has found a $\beta$ index with an appropriate difference compared to the MCS method. Fig. 14 presents the statistical scattering of the solution of 30 independent runs of the algorithm for the 3-bay 15-story frame.

Fig. 15 shows the values of random variables at the MPP obtained from each algorithm on the Probability Density Function (PDF) of standard normal distribution diagram. According to this figure, it can be seen that the values of the cross-sectional areas and the moment of inertia of

Table 6 Statistical optimization results obtained by algorithms for the 3-bay 15-story frame

\begin{tabular}{lccccc}
\hline & EVPS & EVPS-MDM & VPS & VPS-MDM & MCS \\
\hline Best $\beta$ & 2.7144 & 2.7071 & 2.8841 & 2.7971 & - \\
Average $\beta$ & 2.8086 & 2.8512 & 2.9744 & 2.9526 & 2.6366 \\
Worst $\beta$ & 3.2652 & 3.2230 & 3.1513 & 3.0567 & - \\
Std $\beta$ & 0.1263 & 0.1298 & 0.0733 & 0.0494 & 0.0115 \\
\hline
\end{tabular}

the group of elements are approximately the same as the mean values, and decreasing the modulus of elasticity and increasing the lateral load relative to their mean values has created the MPP.

\subsection{A 3-bay 24-story frame}

Fig. 16 illustrates the schematic, applied loads and the numbering of the member groups for this frame structure. This frame consists of 100 joints and 168 elements. The element grouping results in 4 beam sections and 16 column sections. The material has a modulus of elasticity equal to $E=205 \mathrm{GPa}$ (29 $732 \mathrm{ksi}$ ) and the yield stress of $f_{y}=230.28 \mathrm{MPa}(33.4 \mathrm{ksi})$. The number of random variables in this problem are 46 variables (consisting of 20 cross-sectional area, 20 moment of inertia, 4 gravity load and 1 lateral load and modulus of elasticity) which their probabilistic properties are reported in Table 7.

The reliability index for probabilistic constraints is the maximum lateral displacement of the last story (less than allowable value equal to 11.52 in or $26.26 \mathrm{~cm}$ ).The reliability index is calculated for the optimal design obtained from the SDE algorithm presented in Table 8 [32]. 


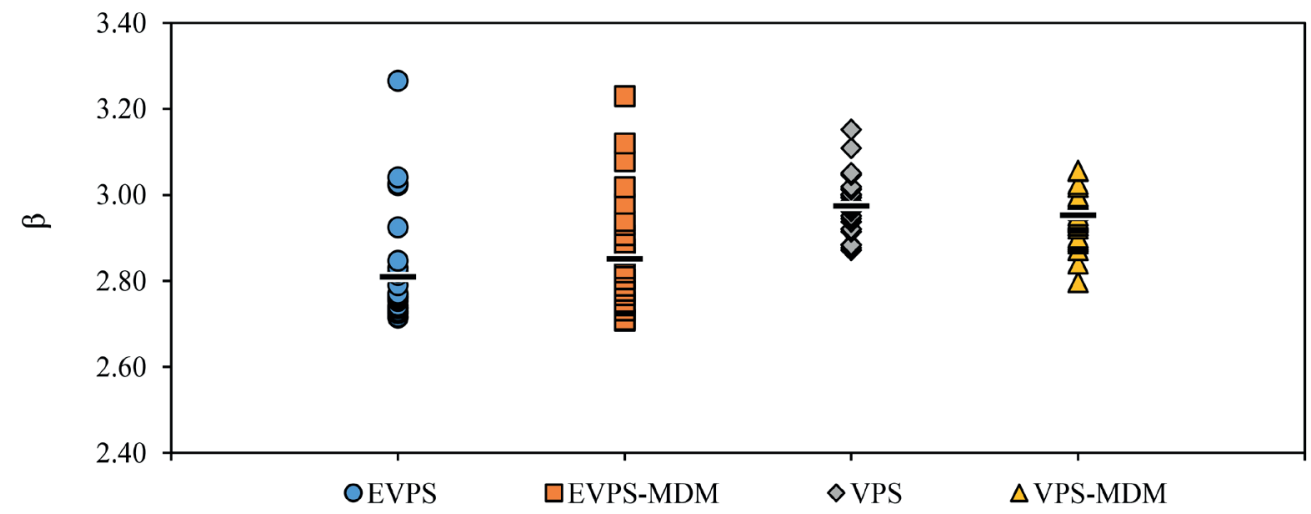

Fig. 14 Statistical scattering of the solution of 30 independent runs of the algorithm for the 3-bay 15-story frame

EVPS)

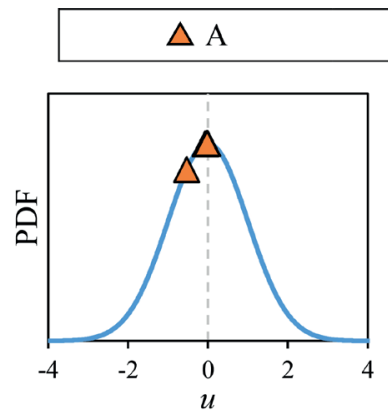

OI $\diamond \mathrm{E}$

$\square \mathrm{P}$
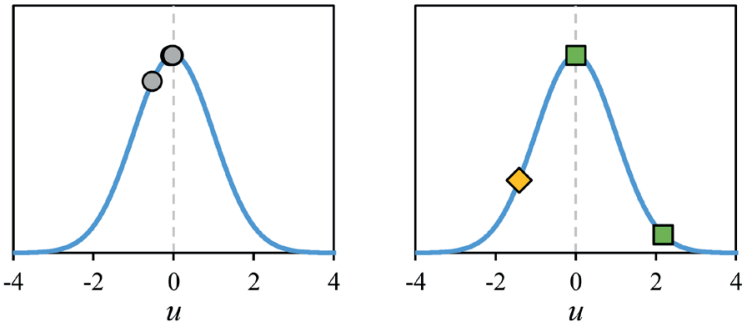

EVPS-MDM)
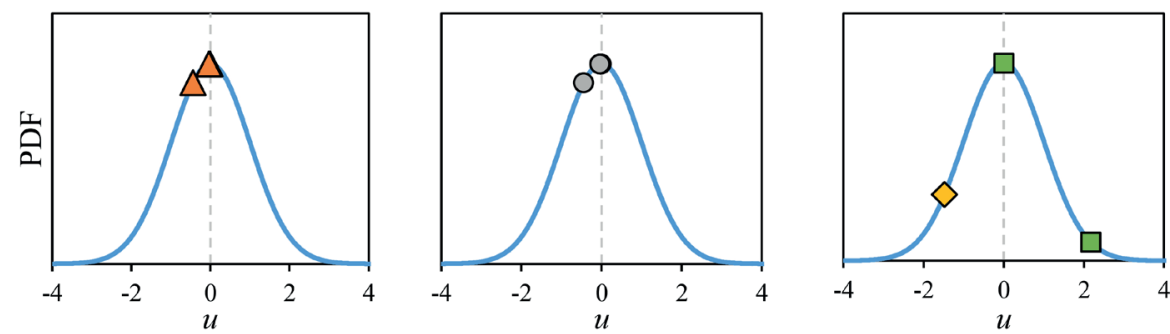

VPS)
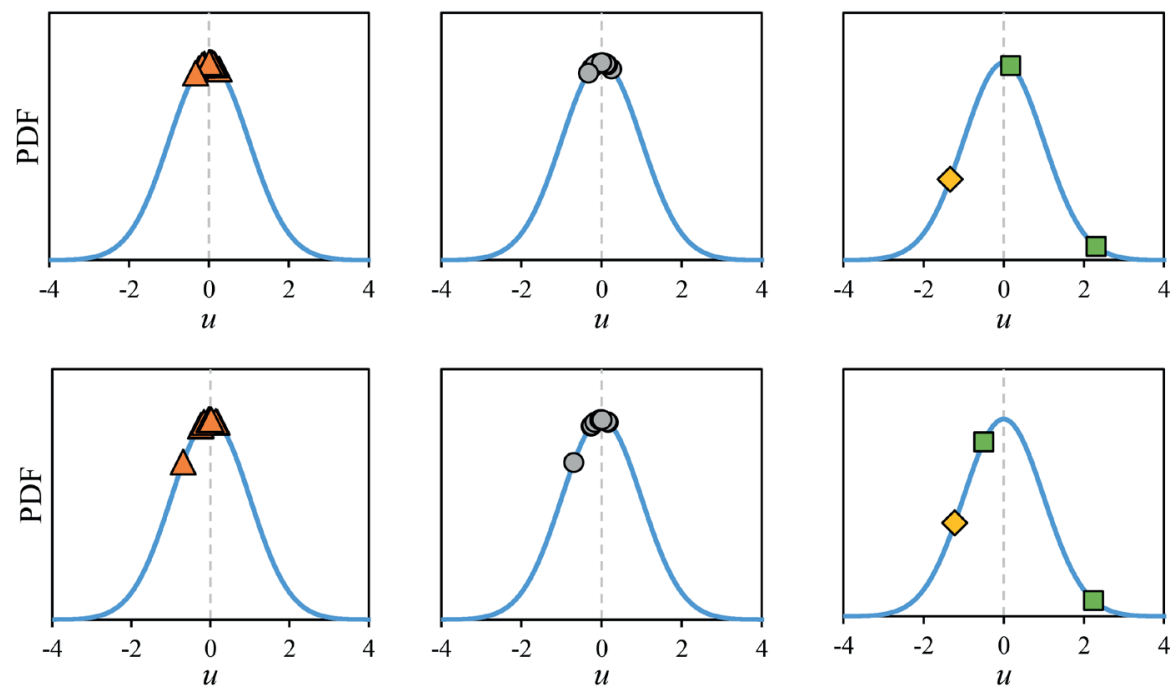

Fig. 15 The MPP in standard normal space (U-space) obtained from each algorithm for the 3-bay 15-story frame 
$\mathrm{W} 1=4.378 \mathrm{kN} / \mathrm{m}(300 \mathrm{Ib} / \mathrm{ft}), \mathrm{W} 2=6.362 \mathrm{kN} / \mathrm{m}(436 \mathrm{Ib} / \mathrm{ft})$ $\mathrm{W} 3=6.917 \mathrm{kN} / \mathrm{m}(474 \mathrm{Ib} / \mathrm{ft}), \mathrm{W} 4=5.954 \mathrm{kN} / \mathrm{m}(408 \mathrm{Ib} / \mathrm{ft})$

\section{$25.63 \mathrm{kN}$} $(5761.85 \mathrm{Ib})$ $25.63 \mathrm{kN}$ $(5761.85 \mathrm{Ib})$

$25.63 \mathrm{kN}$ (5761.85 Ib) $25.63 \mathrm{kN}$ (5761.85 Ib) $25.63 \mathrm{kN}$ (5761.85 Ib) $25.63 \mathrm{kN}$ (5761.85 Ib $25.63 \mathrm{kN}$ (5761.85 Ib) $25.63 \mathrm{kN}$ (5761.85 Ib) $25.63 \mathrm{kN}$ (5761.85 Ib) $25.63 \mathrm{kN}$ (5761.85 Ib) $25.63 \mathrm{kN}$ (5761.85 Ib) $25.63 \mathrm{kN}$ (5761.85 Ib) $25.63 \mathrm{kN}$ (5761.85 Ib) $25.63 \mathrm{kN}$ (5761.85 Ib) $25.63 \mathrm{kN}$ (5761.85 Ib) $25.63 \mathrm{kN}$ (5761.85 Ib) $25.63 \mathrm{kN}$ (5761.85 Ib) $25.63 \mathrm{kN}$ (5761.85 Ib) $25.63 \mathrm{kN}$ (5761.85 Ib) $25.63 \mathrm{kN}$ (5761.85 Ib)

$25.63 \mathrm{kN}$ (5761.85 Ib) $25.63 \mathrm{kN}$ (5761.85 Ib) $25.63 \mathrm{kN}$ (5761.85 Ib) $25.63 \mathrm{kN}$ (5761.85 Ib)

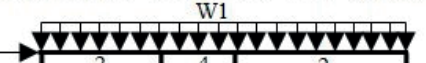

b)

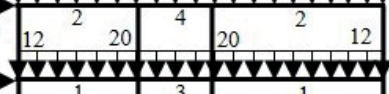

$\rightarrow$

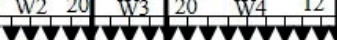
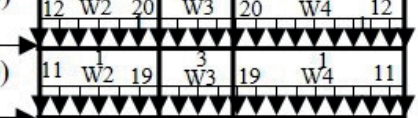

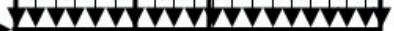

$\rightarrow$ 1
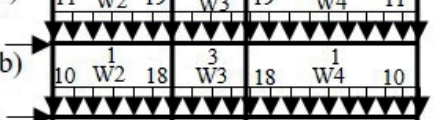

$\rightarrow$

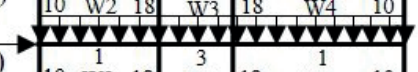

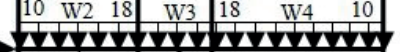
\begin{tabular}{ccc|c|cc}
\hline & 1 & & 3 & & 1 \\
9 & $\mathrm{~W} 2$ & 17 & $\mathrm{~W} 3$ & 17 & $\mathrm{~W} 4$
\end{tabular} $\frac{1}{\Delta \Delta \Delta \Delta \Delta \Delta \Delta \Delta \Delta \Delta \Delta \Delta \Delta}$

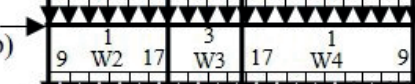

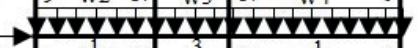
$\rightarrow 9$

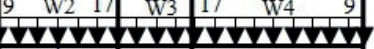

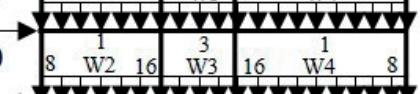
24@3.65m

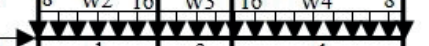
$(12 \mathrm{ft})$
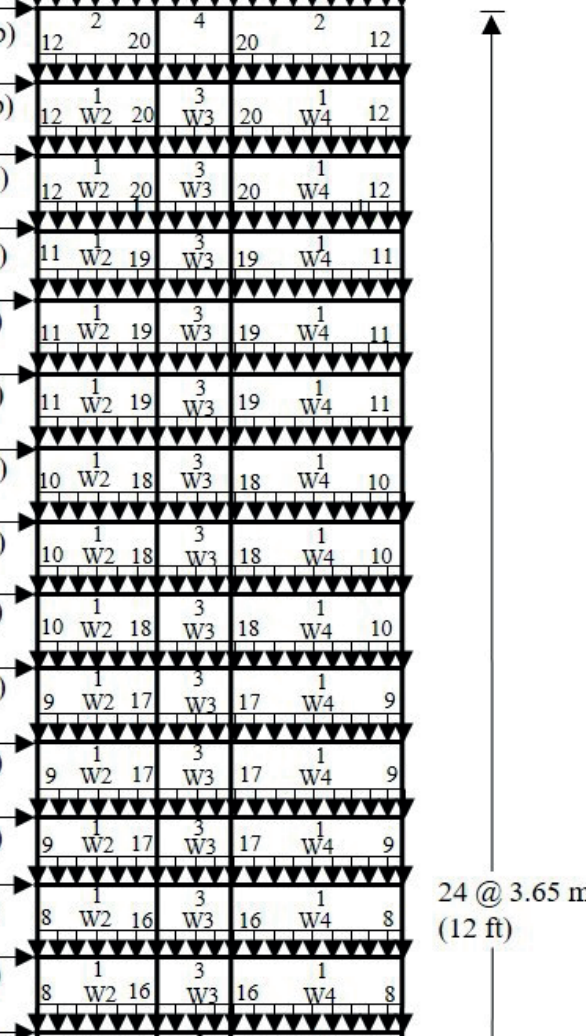

b) \begin{tabular}{ll|lll}
16 & $\mathrm{~W}$ & 16 & $\mathrm{~W}$ & 8 \\
\hline
\end{tabular} 7 $\rightarrow \frac{1}{7}$ W3 $15 \quad 154$

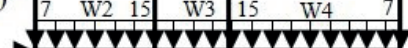

Ib)
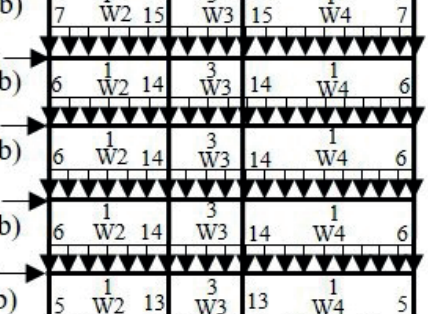

$\rightarrow$

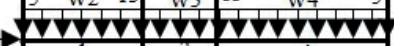

$\rightarrow$
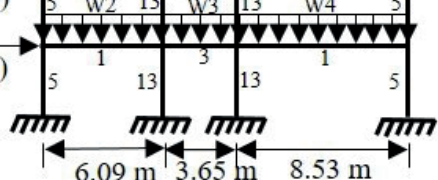

$(20 \mathrm{ft}) \quad(12 \mathrm{ft}) \quad(28 \mathrm{ft})$

Fig. 16 Schematic of the 3-bay 24-story frame

Figs. 17 and 18 show the performance of the algorithms for best and mean results in 30 independent runs, respectively. Fig. 17 shows the comparison of the results of all algorithms in 30 independent runs for the 4-bay 24-story frame in descending order for both algorithms.
Table 7 The probabilistic properties of random variables for 3-bay 24-story frame

\begin{tabular}{lcccc}
\hline $\begin{array}{l}\text { Random Variable, } \\
\text { unit }\end{array}$ & $\begin{array}{c}\text { Type of } \\
\text { probability } \\
\text { distribution }\end{array}$ & $\begin{array}{c}\text { Number } \\
\text { of } \\
\text { variables }\end{array}$ & Mean & COV \\
\hline $\begin{array}{l}\text { Modulus of } \\
\text { elasticity (E), GPa }\end{array}$ & Normal & 1 & 205 & $5 \%$ \\
Gravity loads, & Normal & 4 & $\begin{array}{c}4.378,6.362, \\
\text { kN/m }\end{array}$ & Normal \\
Lateral load, kN & Nond & $5 \%$ \\
$\begin{array}{l}\text { Cross-sectional } \\
\text { area (A) }\end{array}$ & Normal & 20 & $\begin{array}{c}\text { According to } \\
\text { Table } 8\end{array}$ & $5 \%$ \\
$\begin{array}{l}\text { Moment of } \\
\text { inertia (I) }\end{array}$ & Normal & 20 & $\begin{array}{c}\text { According to } \\
\text { Table } 8\end{array}$ & $5 \%$ \\
\hline
\end{tabular}

Table 8 Selected design sections of the 3-bay 24-story frame

\begin{tabular}{lccc}
\hline $\begin{array}{l}\text { Element group } \\
\text { number }\end{array}$ & Section & $\begin{array}{c}\text { Element group } \\
\text { number }\end{array}$ & Section \\
\hline 1 & $\mathrm{~W} 30 \times 90$ & 11 & $\mathrm{~W} 14 \times 34$ \\
2 & $\mathrm{~W} 14 \times 68$ & 12 & $\mathrm{~W} 14 \times 61$ \\
3 & $\mathrm{~W} 27 \times 84$ & 13 & $\mathrm{~W} 14 \times 90$ \\
4 & $\mathrm{~W} 10 \times 39$ & 14 & $\mathrm{~W} 14 \times 145$ \\
5 & $\mathrm{~W} 14 \times 159$ & 15 & $\mathrm{~W} 14 \times 132$ \\
6 & $\mathrm{~W} 14 \times 82$ & 16 & $\mathrm{~W} 14 \times 193$ \\
7 & $\mathrm{~W} 14 \times 90$ & 17 & $\mathrm{~W} 14 \times 90$ \\
8 & $\mathrm{~W} 14 \times 53$ & 18 & $\mathrm{~W} 14 \times 99$ \\
9 & $\mathrm{~W} 14 \times 61$ & 19 & $\mathrm{~W} 14 \times 48$ \\
10 & $\mathrm{~W} 14 \times 90$ & 20 & $\mathrm{~W} 14 \times 22$ \\
\hline
\end{tabular}

The performance of the EVPS-MDM and VPS-MDM algorithms are better than the EVPS and VPS algorithms, respectively, as shown in the Figs. 17-19. The best, the worst, and the mean of the answers of both algorithm and the value of the $\beta$ index achieved from the MCS method are reported in Table 9. In this table the capability of the EVPS-MDM and VPS-MDM to find the reliability index are better than EVPS and VPS-MDM, respectively and also, this algorithm has found a $\beta$ index with an appropriate difference compared to the MCS method. Fig. 20 presents the statistical scattering of the solution of 30 independent runs of the algorithm for the 3-bay 24-story frame.

Fig. 21 shows the values of random variables at the MPP obtained from each algorithm on the Probability Density Function (PDF) of standard normal distribution diagram. According to this figure, it can be seen that the values of the cross-sectional areas and the moment of inertia of the group of elements are approximately the same as the mean values, and decreasing the modulus of elasticity and increasing the lateral load relative to their mean values has created the MPP. 

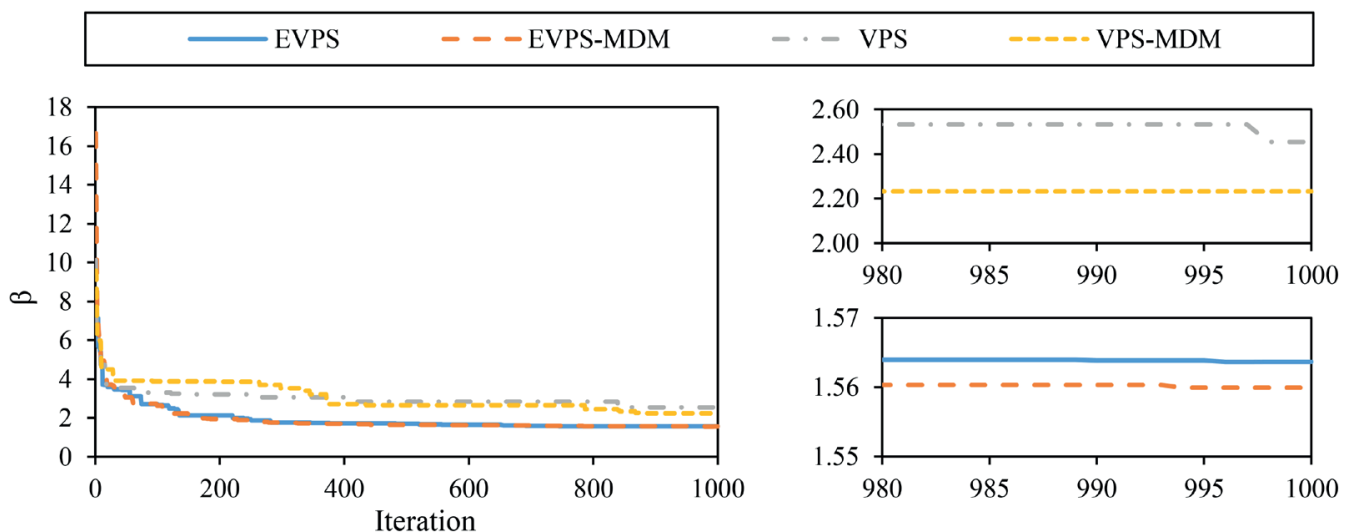

Fig. 17 The convergence diagrams for the best run of the both algorithms for the 3-bay 24-story frame

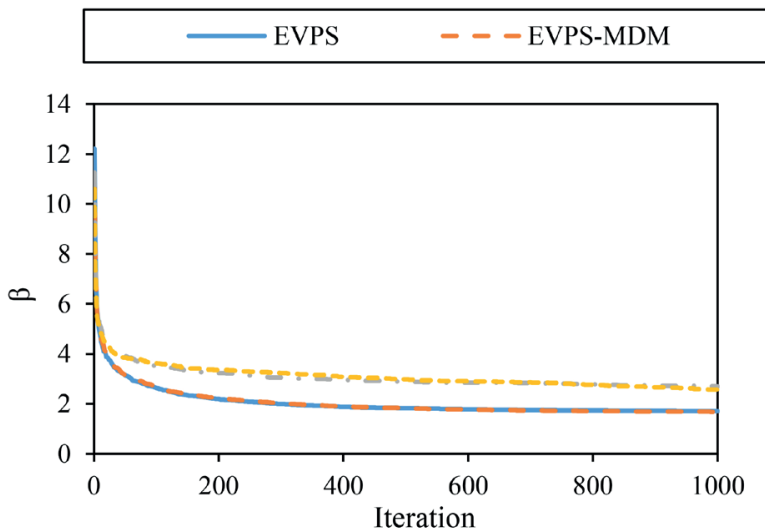

$-\cdots$ VPS $\quad-\cdots--$ VPS-MDM

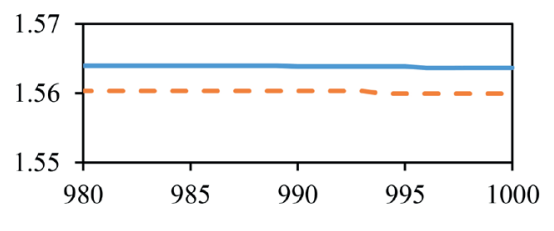

Fig. 18 The convergence diagrams for the average runs of the both algorithms for the 3-bay 24-story frame

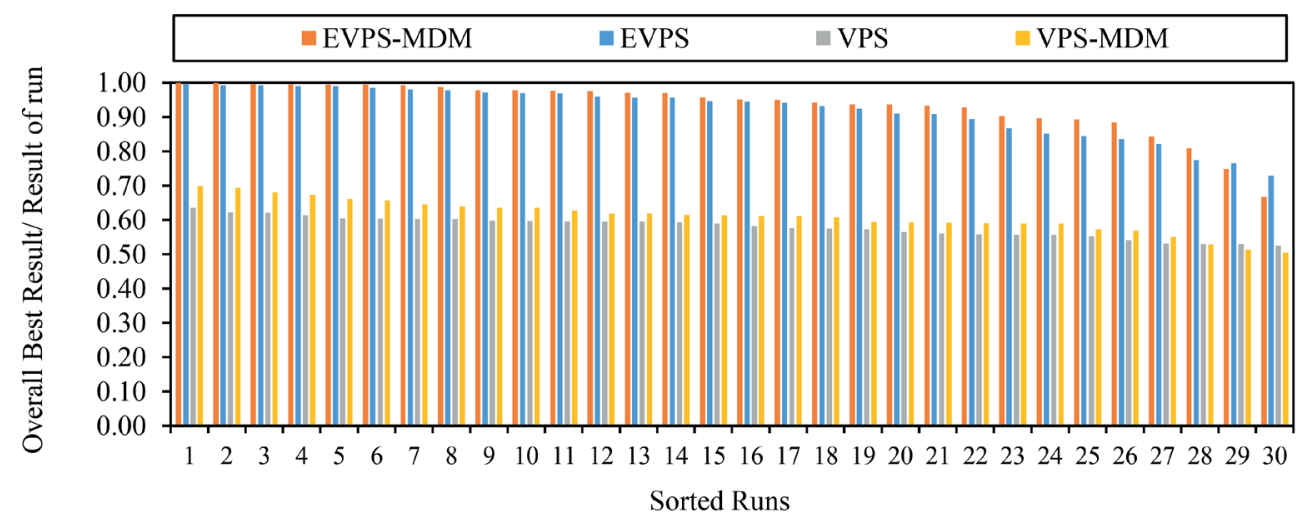

Fig. 19 Comparison of the results of all the algorithms in 30 independent runs for the 3-bay 24-story frame

\section{Conclusions}

In this paper, reliability index of the optimal answer of 3 well-known frame structures were investigated. The objective function is defined as the minimum distance between the limit state function from the origin of the standard normal space; so, the EVPS, VPS, EVPS-MDM and VPS-MDM algorithms are utilized to solve these types of optimization problems. Results show the reliability index values obtained by meta-heuristic algorithms and the MCS method. It is worth noting that the results of the meta-heuristic algorithms
Table 9 Statistical optimization results obtained by algorithms for the

\begin{tabular}{lccccc}
\hline \multicolumn{5}{c}{ 3-bay 24-story frame } \\
\hline Eest $\beta$ & 1.5636 & 1.5599 & 2.4540 & 2.2322 & - \\
Average $\beta$ & 1.7093 & 1.6861 & 2.7002 & 2.5697 & 1.5125 \\
Worst $\beta$ & 2.1412 & 2.3381 & 2.9753 & 3.0894 & - \\
$\operatorname{Std} \beta$ & 0.15434 & 0.17093 & 0.1436 & 0.2121 & 0.0051 \\
\hline
\end{tabular}


(according to less limit state function analysis) compared to those of the MCS method, are acceptable. This is a new capability of the meta-heuristic algorithms. The quality of the answers is also considered with and without the effect of the MDM operator on the EVPS and VPS algorithms.
It should be noted that one of the defining capabilities of Hasofer and Lind method is obtaining the MPP from the reliability index. The results show decreasing the modulus of elasticity and increasing the lateral load relative to their mean values has resulted in the MPP.

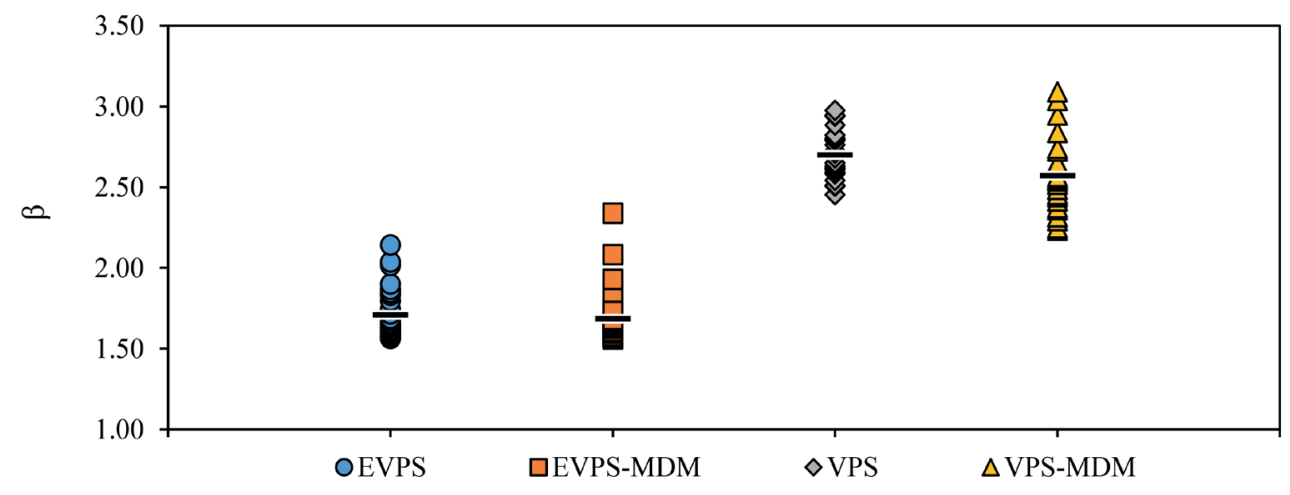

Fig. 20 Statistical scattering of the solution of 30 independent runs of the algorithm for the 3-bay 24-story frame

$\triangle \mathrm{A}$
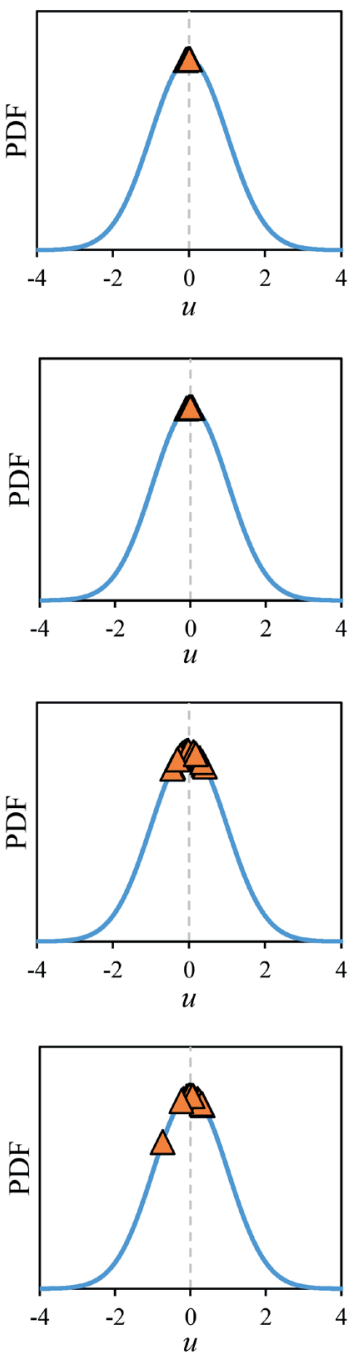

O I
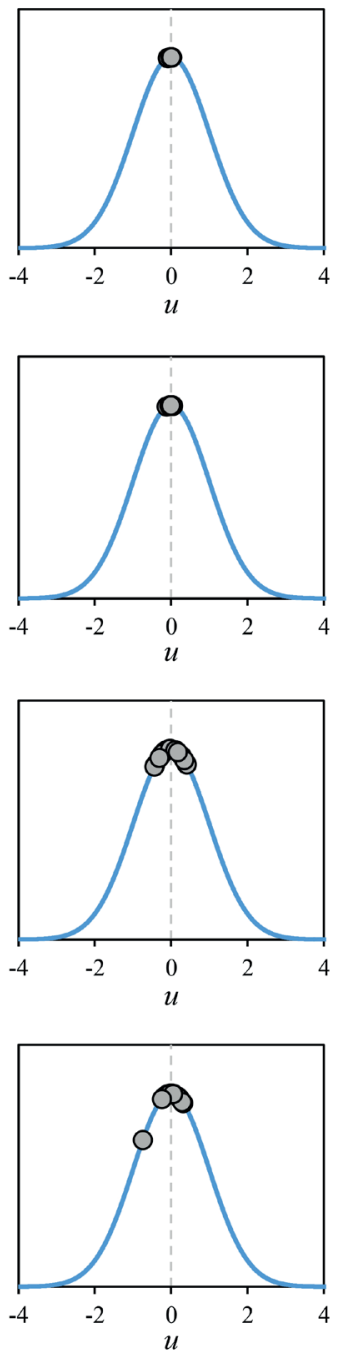

$\square \mathrm{P}$
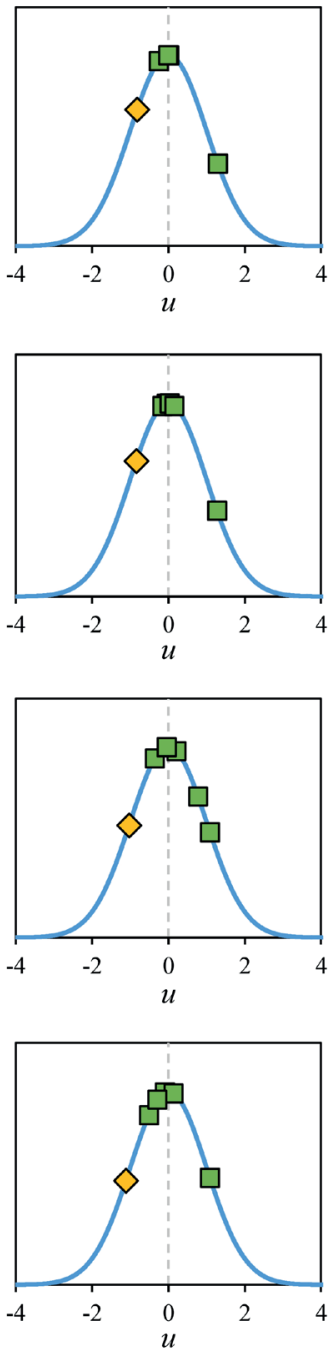

Fig. 21 The MPP in standard normal space (U-space) obtained from each algorithm for the 3-bay 24-story frame 


\section{References}

[1] Das, S., Tesfamariam, S. "Optimization of SMA based damped outrigger structure under uncertainty", Engineering Structures, 222, Article No. 111074, 2020.

https://doi.org/10.1016/j.engstruct.2020.111074

[2] Das, S., Tesfamariam, S., Chen, Y., Qian, Z., Tan, P., Zhou, F. "Reliability-based optimization of nonlinear energy sink with negative stiffness and sliding friction", Journal of Sound and Vibration, 485, Article No. 115560, 2020.

https://doi.org/10.1016/j.jsv.2020.115560

[3] Datta, G., Bhattacharjya, S., Chakraborty, S. "Efficient reliability-based robust design optimization of structures under extreme wind in dual response surface framework", Structural and Multidisciplinary Optimization, 62, pp. 2711-2730, 2020. https://doi.org/10.1007/s00158-020-02606-3

[4] Hoseini Vaez, S. R., Mehanpour, H., Fathali, M. A. "Reliability assessment of truss structures with natural frequency constraints using metaheuristic algorithms", Journal of Building Engineering, 28, Article No. 101065, 2020.

https://doi.org/10.1016/j.jobe.2019.101065

[5] Mishra, S. K., Roy, B. K., Chakraborty, S. "Reliability-based-designoptimization of base isolated buildings considering stochastic system parameters subjected to random earthquakes", International Journal of Mechanical Sciences, 75, pp. 123-133, 2013. https://doi.org/10.1016/j.ijmecsci.2013.06.012

[6] Wang, L., Grandhi, R. V. "Safety index calculation using intervening variables for structural reliability analysis", Computers \& Structures, 59(6), pp. 1139-1148, 1996. https://doi.org/10.1016/0045-7949(96)00291-X

[7] Cui, F., Ghosn, M. "Implementation of machine learning techniques into the Subset Simulation method", Structural Safety, 79, pp. 12-25, 2019.

https://doi.org/10.1016/j.strusafe.2019.02.002

[8] Xiao, N.-C., Zhan, H., Yuan, K. "A new reliability method for small failure probability problems by combining the adaptive importance sampling and surrogate models", Computer Methods in Applied Mechanics and Engineering, 372, Article No. 113336, 2020. https://doi.org/10.1016/j.cma.2020.113336

[9] Zhang, X., Low, Y. M., Koh, C. G. "Maximum entropy distribution with fractional moments for reliability analysis", Structural Safety, 83, Article No. 101904, 2020.

https://doi.org/10.1016/j.strusafe.2019.101904

[10] Movahedi Rad, M., Logo, J. "Plastic behaviour and stability constraints in the reliability based shakedown analysis and optimal design of skeletal structures", Asian Journal of Civil Engineering, 12(4), pp. 395-413, 2011.

[11] Tauzowski, P., Blachowski, B., Lógó, J. "Topology optimization of elasto-plastic structures under reliability constraints: A first order approach", Computers \& Structures, 243, Article No. 106406, 2021. https://doi.org/10.1016/j.compstruc.2020.106406

[12] Zhou, T., Peng, Y. "Kernel principal component analysis-based Gaussian process regression modelling for high-dimensional reliability analysis", Computers \& Structures, 241, Article No. 106358, 2020 .

https://doi.org/10.1016/j.compstruc.2020.106358
[13] Lógó, J., Movahedi Rad, M., Knabel, J., Tauzowski, P. "Reliability based design of frames with limited residual strain energy capacity", Periodica Polytechnica Civil Engineering, 55(1), pp. 13-20, 2011. https://doi.org/10.3311/pp.ci.2011-1.02

[14] Movahedi Rad, M. "Reliability Based Analysis and Optimum Design of Laterally Loaded Piles", Periodica Polytechnica Civil Engineering, 61(3), pp. 491-497, 2017. https://doi.org/10.3311/PPci.8756

[15] Xiao, S., Oladyshkin, S., Nowak, W. "Reliability analysis with stratified importance sampling based on adaptive Kriging", Reliability Engineering \& System Safety, 197, Article No. 106852, 2020. https://doi.org/10.1016/j.ress.2020.106852

[16] Cheng, K., Lu, Z. "Structural reliability analysis based on ensemble learning of surrogate models", Structural Safety, 83, Article No. 101905, 2020.

https://doi.org/10.1016/j.strusafe.2019.101905

[17] Juybari, M. N., Abouei Ardakan, M., Davari-Ardakani, H. "A penalty-guided fractal search algorithm for reliability-redundancy allocation problems with cold-standby strategy", Proceedings of the Institution of Mechanical Engineers, Part O: Journal of Risk and Reliability, 233(5), pp. 775-790, 2019. https://doi.org/10.1177/1748006x19825707

[18] Mellal, M. A., Al-Dahidi, S., Williams, E. J. "System reliability optimization with heterogeneous components using hosted cuckoo optimization algorithm", Reliability Engineering \& System Safety, 203, Article No. 107110, 2020. https://doi.org/10.1016/j.ress.2020.107110

[19] Peiravi, A., Ardakan, M. A., Zio, E. "A new Markov-based model for reliability optimization problems with mixed redundancy strategy", Reliability Engineering \& System Safety, 201, Article No. 106987, 2020. https://doi.org/10.1016/j.ress.2020.106987

[20] Akhani, M., Kashani, A. R., Mousavi, M., Gandomi, A. H. "A hybrid computational intelligence approach to predict spectral acceleration", Measurement, 138, pp. 578-589, 2019. https://doi.org/10.1016/j.measurement.2019.02.054

[21] Kaveh, A. "Advances in Metheuristic Algorithms in Civil Engineering", 2nd edition, Springer, Switzerland, 2017.

[22] Kaveh, A., Hosseini Vaez, S. R., Hosseini, P., Fathali, M. A. "A New Two-Phase Method for Damage Detection in Skeletal Structures", Iranian Journal of Science and Technology, Transactions of Civil Engineering, 43(suppl1), pp. 49-65, 2019. https://doi.org/10.1007/s40996-018-0190-4

[23] Mousavi, M., Holloway, D., Olivier, J. C., Alavi, A. H., Gandomi, A. H. "A Shannon entropy approach for structural damage identification based on self-powered sensor data", Engineering Structures, 200, Article No. 109619, 2019. https://doi.org/10.1016/j.engstruct.2019.109619

[24] Shabani, A., Asgarian, B., Salido, M., Asil Gharebaghi, S. "Search and rescue optimization algorithm: A new optimization method for solving constrained engineering optimization problems", Expert Systems with Applications, 161, Article No. 113698, 2020. https://doi.org/10.1016/j.eswa.2020.113698 
[25] Kaveh, A., Motie Share, M. A., Moslehi, M. "Magnetic charged system search: a new meta-heuristic algorithm for optimization", Acta Mechanica, 224, pp. 85-107, 2013. https://doi.org/10.1007/s00707-012-0745-6

[26] Kaveh, A., Ilchi Ghazaan, M. "Vibrating particles system algorithm for truss optimization with multiple natural frequency constraints", Acta Mechanica, 228(1), pp. 307-322, 2017. https://doi.org/10.1007/s00707-016-1725-z

[27] Kaveh, A., Hoseini Vaez, S. R., Hosseini, P. "Enhanced vibrating particles system algorithm for damage identification of truss structures", Scientia Iranica, 26(1), pp. 246-256, 2019. https://doi.org/10.24200/sci.2017.4265

[28] Kaveh, A., Farhoudi, N. "Dolphin monitoring for enhancing metaheuristic algorithms: Layout optimization of braced frames", Computers \& Structures, 165, pp. 1-9, 2016. https://doi.org/10.1016/j.compstruc.2015.11.012

[29] Kaveh, A., Hoseini Vaez, S. R., Hosseini, P., Ezzati, E. "Layout Optimization of Planar Braced Frames Using Modified Dolphin Monitoring Operator", Periodica Polytechnica Civil Engineering, 62(3), pp. 717-731, 2018.

https://doi.org/10.3311/PPci.11654
[30] Hosseini, P., Hoseini Vaez, S. R., Fathali, M. A., Mehanpour, H. "Reliability Assessment of Transmission Line Towers Using Metaheuristic Algorithms", International Journal of Optimization in Civil Engineering, 10(3), pp. 531-551, 2020. [online] Available at: http://ijoce.iust.ac.ir/article-1-450-en.html

[31] Hasofer, A. M., Lind, N. C. "Exact and invariant second-moment code format", Proceedings of the American Society of Civil Engineers. Journal of the Engineering Mechanics Division, 100(1), pp. 111-121, 1974.

[32] Kaveh, A., Hoseini Vaez, S. R., Hosseini, P. "Performance of the Modified Dolphin Monitoring Operator for Weight Optimization of Skeletal Structures", Periodica Polytechnica Civil Engineering, 63(1), pp. 30-45, 2019.

https://doi.org/10.3311/PPci.12544 